\title{
Antioxidant Activity of Coumarine Compounds
}

\author{
Yasameen K. Al-Majedy , Hiba H. Ibraheem, Liblab Sami Jassim and Ahmed A. Al-Amiery \\ Branch of Chemistry, Department of Applied Science, University of Technology (UOT), \\ Baghdad 10001, Iraq. \\ * Corresponding Author: yasmin.chem79@gmail.com
}

\begin{abstract}
Synthesis of coumarins, that were a structurally motivating antioxidant action, was finished in our article. Four components are condensed in the synthesis 4-hydroxycoumarin, 5,5-dimethyl-1,3cyclohexanedione, and aromatic aldehydes, using tetrabutylammonium bromide (TBAB), diammonium hydrogen phosphate (DAHP), respectively to yield target compounds(1-4). The present methods have advantages, including one-pot synthesis, excellent yields, short reaction times, and easy isolation of product. All catalysts utilized in our study could be reused several times without losing their catalytic efficiency. The structures of the synthesized compounds were elucidating by spectro-scopically methods, Infrared Spectra FT-IR and ${ }^{1} \mathrm{H}$ and ${ }^{13} \mathrm{C}$ Nuclear/Magnetic/Resonance Spectra and elemental analysis techniques, melting point and thin layer chromatography. The scavenging activities of individual molecules were tested vs. stable free radical(1,1-Diphenyl-2-picrylhydrazyl (DPPH)), the results were compared to the Gallic acid. The results show that most of the compounds exhibited higher antioxidant activates than the standards in different concentration range. The highest efficiency scavenging activity was found for compound 2 $(88.0 \pm 1 \%)$ followed by compounds $3(83 \pm 0.5 \%)$. The component of the integrated mixes as cell reinforcements was likewise examined. [DOI: 10.22401/ANJS.22.1.01]
\end{abstract}

Keywords: antioxidant activity; coumarin; (1,1-Diphenyl-2-picrylhydrazyl (DPPH)).

\section{Introduction}

Coumarins comprises of a sweet-smelling ring combined to a consolidated pyrone ring, [1] and across the board in plant kingdom. Coumarin right off the bat separated from tonka beans and had been utilized as an enhancing agent, [2] and its subsidiaries indicate pharmacological exhibitions, for example, antitumor, anti-inflammatory, [3] ant tuberculosis, [4] antiviral,[5] alzheimer [6] and antimicrobial [7]. Also, subordinates that functionalized with heterocyclic moieties, for example, azetidine, thiazolidine, thiazole could extensively expand the therapeutic productivity. $[8,9]$ activities. In recent years, there is much interest in the search for antioxidants from natural, industrial sources. As antioxidants inhibit and scavenge radicals, they play an important role in protecting humans from infections and degenerative diseases. As such antioxidants can be defined as any substrate that significantly delays or prevents oxidation. According to [10] in comparison with an oxidizable substrate (lipid, protein, carbohydrate, or DNA) only low concentration of antioxidant is required to delay or prevent a few obsessive conditions, for example, aggravation, carcinogenesis, atherogenes and furthermore in the maturing procedure and additionally after harmful exposures to xenobiotics [11-13]. Interest in the discovery of new antioxidant agents has surmounted increased, since the implication of oxidative damages in many pathology cases. The other class of compounds that has caught much attention is polyphenols. This class of mixes include flavonoids (i.e. flavones, flavonols, flavanones, flavononols, chalcones and flavan-3-ols), lignins, tocopherols, tannins and phenolic acids [14]. However, the flavonoids constitute the largest group of phenolic compounds with an extensive variety of compound and organic exercises including antioxidant and free radical scavenging properties [15]. Also the phenolic compounds can act as antioxidants by chelating metal ions, preventing the formation of radicals and moving the antioxidant endogenous system forward [16]. Each method has a different catalyst, namely, tetrabutylammonium bromide (TBAB), diammoniumhydrogen phosphate (DAHP). All catalysts are recyclable and have reproducible results without any loss of its activity. All synthesized compounds were evaluated for their antioxidant activity. Reaction sequences of the synthesized compounds are appeared in Scheme (1). 


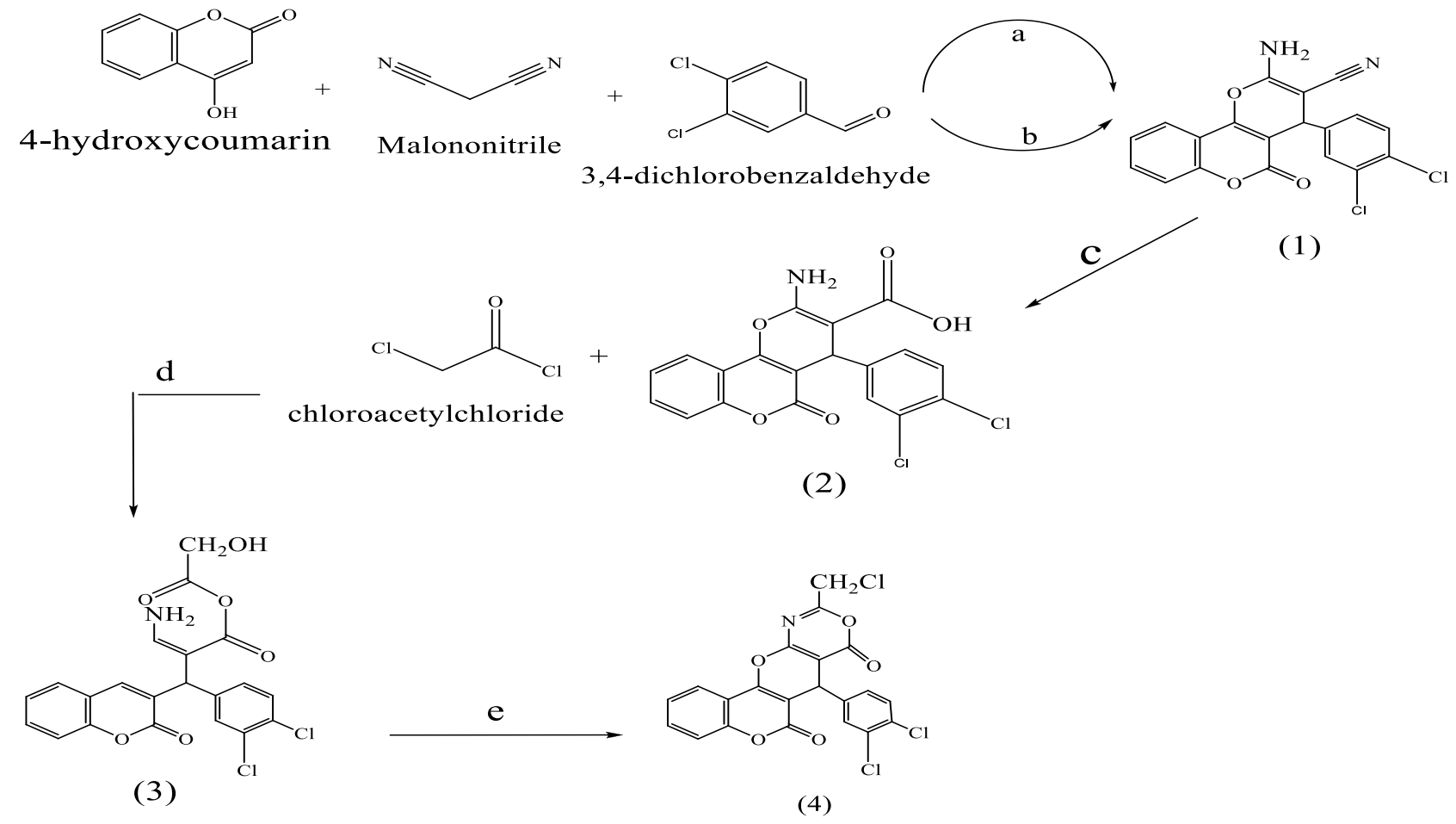

Scheme (1): Reaction sequences of the synthesized compounds.

Reagents and Conditions:

$\mathrm{a}=$ Tetrabutylammoniumbromide (TBAB) / reflux;

$\mathrm{b}=$ diammonium hydrogen phosphate (DAHP) / reflux;

$\mathrm{c}=$ hydrolysis; $\mathrm{d}=$ benzene/ reflux; $\mathrm{e}=\mathrm{H}_{2} \mathrm{SO}_{4} /$ reflux.

\section{Experimental Section}

\subsection{General Information}

The compounds and solvents utilized were provided by Sigma/Aldrich. The IR spectra of prepared molecules have been done by Nicolet 6700 spectrophotometer and the qualities are communicated in $\mathrm{cm}^{-1}$. NMR spectra were recorded utilizing an AVANCE III $600 \mathrm{MHz}$ spectrometer (Bruker, Billerica, MA, USA), utilizing DMSO-d6 as an interior standard. Elemental analysis was done on an Elementar Vario El III Carlo Erba 1108 basic analyzer (Italy).

\subsection{Chemistry}

\subsubsection{Synthesis of 2-amino-4-(3,4} dichlorophenyl)-5-oxo-4, 5-dihydropyrano (3, 2-c) chromene-3-carbonitrile (1)

a. Tetrabutylammonium Bromide (TBAB) as catalyst for synthesis of compound (1)

The reactants, namely 4-hydroxycoumarin (0.162g;10mmol)with3,4dichlorobenzaldehyde (5 mmol), malononitrile (15 mmol) and tetrabutylammonium bromide $(10 \mathrm{~mol} \%)$ were refluxed. Then, the mixture was cooled to room temperature. The solid mass was filtered and dried then recrystallized from ethanol [17]. Then the compound was characterized by spectroscopic and physical data, yields $70 \%$.M.P $\left(230-231^{\circ} \mathrm{C}\right)$.

\section{b. DiammoniumHydrogen Phosphate (DAHP) as catalyst for synthesis of compound(1)}

The reactants in $50 \mathrm{ml}$ of aqueous ethanol (50\% ethanol: $50 \%$ water), including 4hydroxycoumarin $(0.162 \mathrm{~g} ; 10 \mathrm{mmol}), 3$, 4dichlorobenzaldehyde(10mmol), malononitrile (12 mmol) and diammonium hydrogen phosphate (26.4 mg, $10 \mathrm{~mol} \%$ ), were stirred for $4 \mathrm{hr}$. at room temperature. After finish of the reaction, the solid mass was filtered and washed with aqueous ethanol [18]. Then the compound was characterized by spectroscopic and physical data., yields 60\%. M.P (229$\left.230^{\circ} \mathrm{C}\right) ;{ }^{1} \mathrm{H}-\mathrm{NMR}: \delta 4.25(\mathrm{~s}, 1 \mathrm{H}, \mathrm{CH}), \delta 7.1$ $(\mathrm{s}, 1 \mathrm{H}, \mathrm{CH}), \delta 7.80(\mathrm{dd}, 2 \mathrm{H}), \delta 7.40-7.81$ (m, $1 \mathrm{H}, \mathrm{C}-\mathrm{H}$ aromatic ring), $\delta 8.45\left(\mathrm{~s}, \mathrm{NH}_{2}\right)$; ${ }^{13} \mathrm{CNMR}\left(\mathrm{CDCl}_{3}\right)$ : 42, 58.2, 109, 115.0, 126.1, 127.0, 151.1, 160.5, 162.1 and 164.5; FT-IR: $3382.8 \mathrm{~cm}^{-1} \quad\left(\mathrm{NH}_{2}\right), \quad 3185.0 \mathrm{~cm}^{-1} \quad(\mathrm{C}-\mathrm{H}$ aromatic), $\quad 1706.2 \mathrm{~cm}^{-1} \quad(\mathrm{C}=\mathrm{O}, \quad$ lactone $)$, 
$2212 \mathrm{~cm}^{-1} \quad(\mathrm{C} \equiv \mathrm{N}), \quad 1637.0 \quad \mathrm{~cm}^{-1} \quad(\mathrm{C}=\mathrm{C}$ aromatic); Analysis: The theoretical calculation for $\mathrm{C}_{19} \mathrm{H}_{10} \mathrm{C}_{12} \mathrm{~N}_{2} \mathrm{O}_{3}$ : C $59.24 \% \mathrm{H}$ $2.62 \% \mathrm{~N} 7.27 \%$, while the experimental calculation shows $\mathrm{C} 58.84 \% \mathrm{H} 2.5 \%$ and $\mathrm{N}$ $7.01 \%$.

\subsubsection{Synthesis of 2-amino-4-(3,4-} dichlorophenyl)-5-oxo-4, 5-dihydropyrano (3, 2-c) chromene-3-carboxylic acid (2)

Aqueous sodium hydroxide solution (1 M, $0.3 \mathrm{ml}$ ) was added to compound (1) and the mixture was heated for $5 \mathrm{~min}$ at $140^{\circ} \mathrm{C}$. The reaction mixture was neutralized by adding hydrochloric acid $(1 \mathrm{M}, 0.3 \mathrm{ml})$ under these conditions we got compound (2) at $20 \mathrm{~min}$. After completion of the reaction, the solid mass was filtered and washed with aqueous ethanol, [19], yields 50\%.M.P $\left(244-245^{\circ} \mathrm{C}\right)$; ${ }^{1} \mathrm{H}-\mathrm{NMR}: \delta 3.83(\mathrm{~s}, 1 \mathrm{H}, \mathrm{CH}), \delta 7.11(\mathrm{~s}, 1 \mathrm{H}$, $\mathrm{CH}), \delta 7.61(\mathrm{dd}, 2 \mathrm{H}), \delta$ 7.12-7.74(m, 1H, C-H aromatic ring), $\delta 8.5\left(\mathrm{~s}, \mathrm{NH}_{2}\right), \delta 11.0(\mathrm{~s}, \mathrm{OH})$; FT-IR: 3220 $\left(\mathrm{NH}_{2}\right), 3304 \mathrm{~cm}^{-1}(\mathrm{OH}) ; 3090.3$ $\mathrm{cm}^{-1} \quad\left(\mathrm{C}-\mathrm{H}\right.$ aromatic), $1650 \mathrm{~cm}^{-1} \quad(\mathrm{C}=\mathrm{O}$, lactone), $1713 \mathrm{~cm}^{-1}(\mathrm{C}=\mathrm{O}$, carboxylic), 1626.3 $\mathrm{cm}^{-1} \quad(\mathrm{C}=\mathrm{C}$ aromatic $)$ Analysis: The theoretical calculation for $\mathrm{C}_{19} \mathrm{H}_{11} \mathrm{C}_{12} \mathrm{NO}_{5}$ : C $56.46 \%$ H $2.74 \%$ N $3.47 \%$, while the experimental calculation shows $\mathrm{C} 56.11 \% \mathrm{H}$ $2.3 \%$ and $\mathrm{N} 3.3 \%$.

\subsubsection{Synthesis of 3-amino-2-((3,4-} dichlorophenyl)(2-oxo-2H-chromen-3yl)methyl)acrylic 2-chloroacetic anhydride (3)

In $100 \mathrm{ml} \mathrm{RBF},(0.02 \mathrm{~mol})$ of compound (2) in $4 \mathrm{ml}$ ethanol was mixed on the attractive stirrer for $10 \mathrm{~min}$. Four equivalent of chloroacetylchloride $(0.02 \mathrm{~mol})$ was included drop shrewd for $1 \mathrm{hr}$. Response blend was kept for mixing for 24 squirm response blend was cooled, filled super cold water $(50 \mathrm{ml})$ containing a drop of pyridine and mixed until the point when the oil sets. Unrefined item was sifted, washed with icy water and dried. The product was recrystallized from ethanol [20], yields $45 \%$. M.P $\left(268-269^{\circ} \mathrm{C}\right) ;{ }^{1} \mathrm{H}-\mathrm{NMR}: \delta 2.3$ $(\mathrm{s}, 1 \mathrm{H}, \mathrm{NH}), \delta 3.81(\mathrm{~s}, 1 \mathrm{H}, \mathrm{CH}), \delta 7.1(\mathrm{~s}, 1 \mathrm{H}$, $\mathrm{CH}), \delta 7.72(\mathrm{dd}, 2 \mathrm{H}), \delta$ 7.4-7.79 (m, 1H, C-H aromatic ring), $\delta 8.4\left(\mathrm{~s}, \mathrm{NH}_{2}\right)$; FT-IR: 3433 $\mathrm{cm}^{-1} \quad\left(\mathrm{NH}_{2}\right), \quad 3328-3246.4 \mathrm{~cm}^{-1} \quad(\mathrm{NH})$, $3054.3 \mathrm{~cm}^{-1}$ (C-H aromatic), $1651 \mathrm{~cm}^{-1}(\mathrm{C}=\mathrm{O})$
$1602.9 \mathrm{~cm}^{-1}(\mathrm{C}=\mathrm{O}$, lactone $)$; Analysis: The theoretical calculation for $\mathrm{C}_{20} \mathrm{H}_{13} \mathrm{Cl}_{3} \mathrm{~N}_{2} \mathrm{O}_{4}$ : C $53.15 \%$ H $2.90 \%$ N $6.20 \%$, while the experimental calculation shows $\mathrm{C} 52.9 \% \mathrm{H}$ $2.85 \%$ and $\mathrm{N} 5.91 \%$.

\subsubsection{Synthesis of 7-(3,4-dichlorophenyl)-10- (chloromethyl) -6H-chromeno [3', 4': $5,6]$ pyrano $[2,3-d][1,3]$ oxazine- $6,8(7 \mathrm{H})$ - dione (4)}

To a solution of $2 \mathrm{mmol}$ of compound (3) in $50 \mathrm{~mL}$ of anhydrous methanol was added concentrated sulphuric acid $(80 \mathrm{mmol})$. The mixture was refluxed on a water bath for 3-4h. Subsequent to cooling, the response content was filled ice-water blend. The precipitated solid was collected by filtration, washed with water and recrystallized from methanol to obtain compound (4) [21], yields 30\%. M.P (210-211 $\left.{ }^{\circ} \mathrm{C}\right) ;{ }^{1} \mathrm{H}-\mathrm{NMR}: \delta 3.9\left(\mathrm{~s}, 2 \mathrm{H}, \mathrm{CH}_{2} \mathrm{Cl}\right), \delta$ $4.4(\mathrm{~s}, 1 \mathrm{H}, \mathrm{CH}), \delta 7.1(\mathrm{~s}, 1 \mathrm{H}, \mathrm{CH}) \delta 7.8(\mathrm{dd}$, $2 \mathrm{H}), \delta$ 7.4-7.79 (m, 1H, C-H aromatic ring); FT-IR: $3181.6 \mathrm{~cm}^{-1}$ (C-H aromatic), 1670.6, $1612.1 \mathrm{~cm}^{-1} \quad(\mathrm{C}=\mathrm{O}$, lactone $), 1570.4 \mathrm{~cm}^{-1}$ $(\mathrm{C}=\mathrm{C}$ aromatic); Analysis: The theoretical calculation for $\mathrm{C}_{21} \mathrm{H}_{10} \mathrm{Cl}_{3} \mathrm{NO}_{5}$ : C $54.52 \% \mathrm{H}$ $2.18 \% \mathrm{~N} 3.03 \%$, while the experimental calculation shows C $54.23 \mathrm{H} 2.0 \%$ and $\mathrm{N}$ $2.91 \%$. 


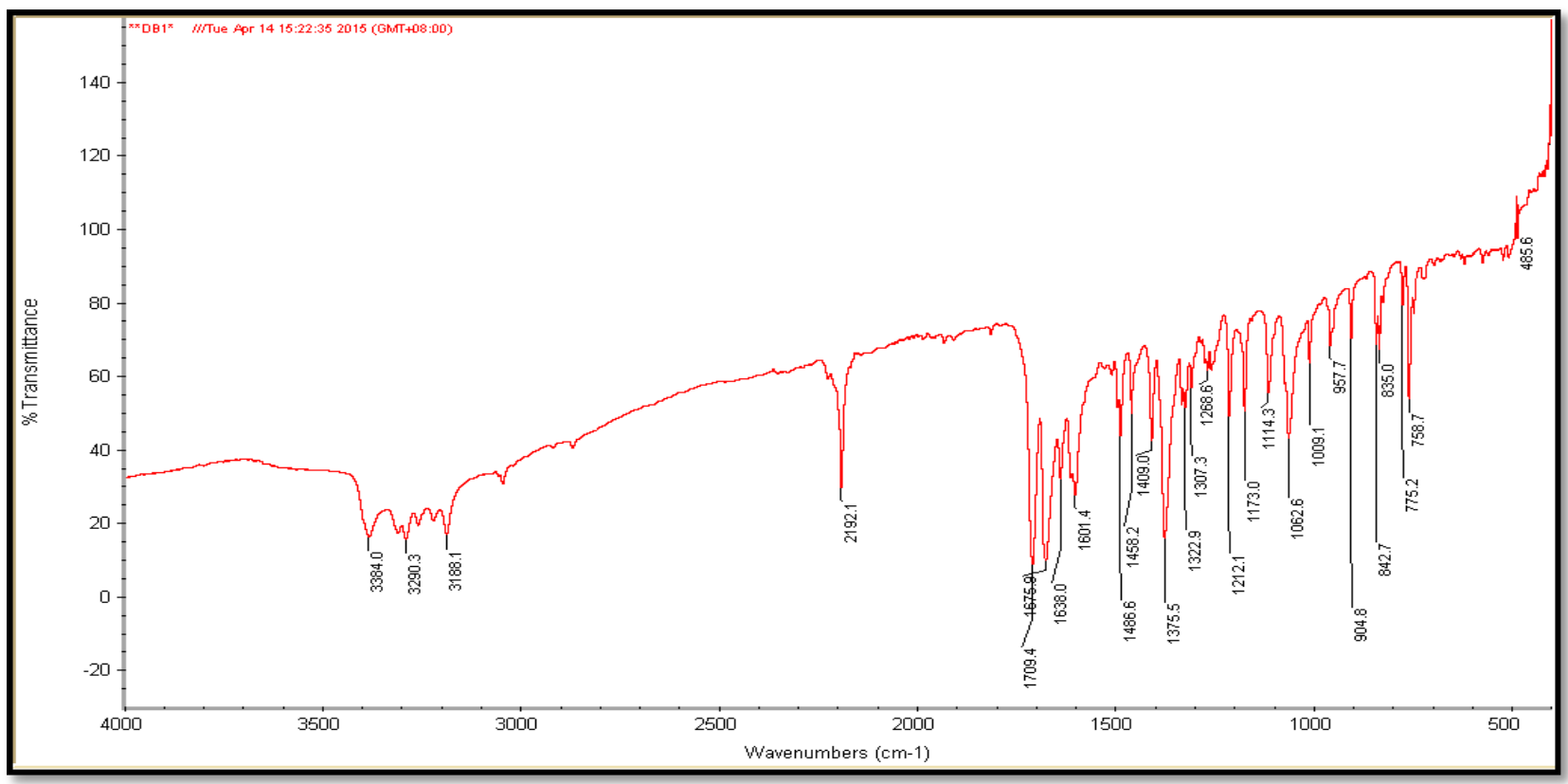

Fig.(1): FTIR spectra of 2-amino-4-(3,4-dichlorophenyl)-5-oxo-4, 5-dihydropyrano (3, 2-c) chromene-3-carbonitrile (1).

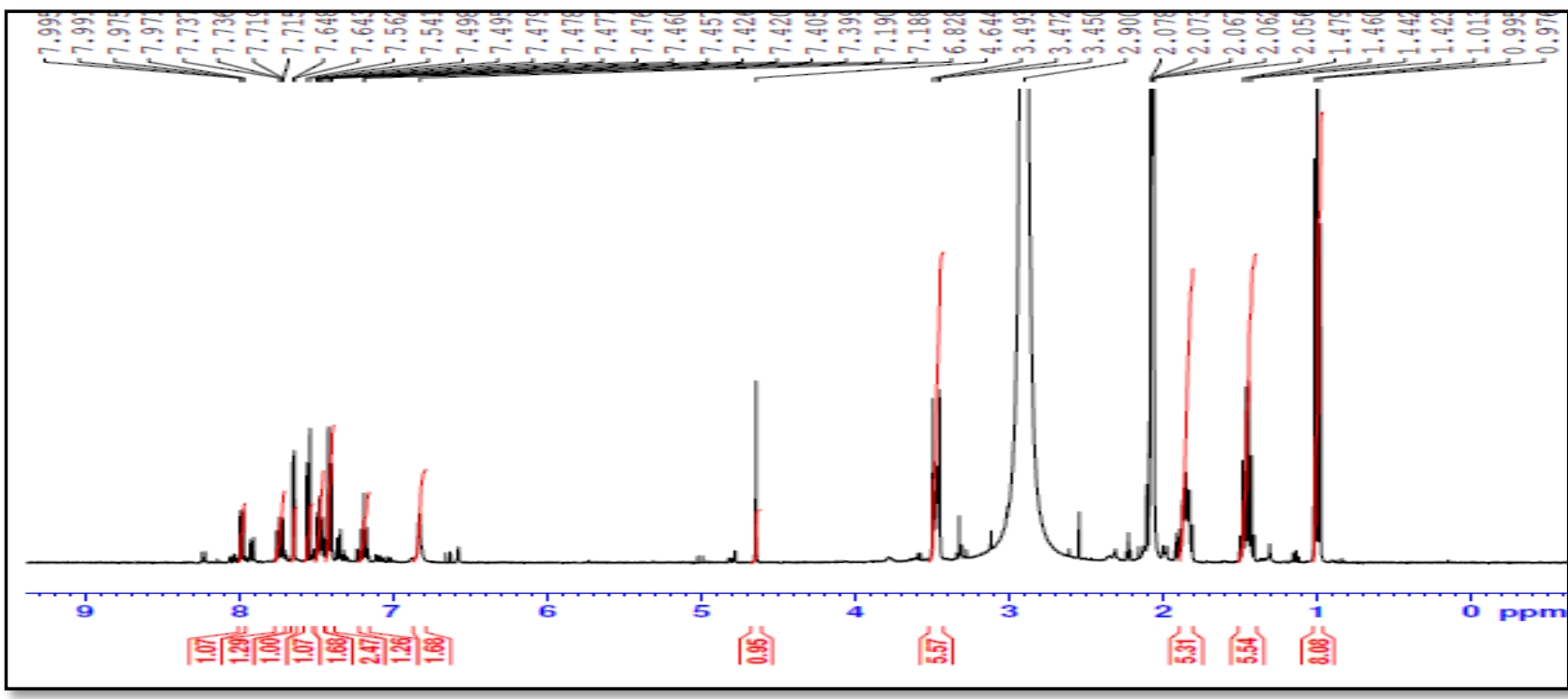

Fig.(2): 1HNMR spectrum of 2-amino-4-(3,4-dichlorophenyl)-5-oxo-4, 5-dihydropyrano (3, 2-c) chromene-3-carbonitrile (1).

\subsection{Antioxidant activity}

\subsection{1.(1,1-Diphenyl-2-picrylhydrazyl)}

Activity

Antioxidant properties of blended coumarin mixes (1-4) were tested spectrophotometrically using 2,2-diphenyl-1picrylhydrazyl radical, [22, 23]. Initially, 0.1 $\mathrm{mL}$ of different concentrations of synthesized compounds $250,500,750$ and $1000 \mu \mathrm{g} / \mathrm{mL}$ and standard ascorbic acid were blended with 1 $\mathrm{mL}$ of $0.2 \mathrm{mM}$ DPPH broke up in methanol. The response blend was brooded oblivious for
$30 \mathrm{~min}$ at $28^{\circ} \mathrm{C}$. The control experiment was carried out as above without the test samples. The DPPH radical searching movement was dictated by estimating the absorbance, at 517 $\mathrm{nm}$ utilizing the UV-VIS spectrophotometer. The reduction of DPPH radical scavenger was calculated relative to the measured absorbance of the control using the following equation (1):

Scavenging effect $\%=\frac{\mathrm{Ao}-\mathrm{A} 1}{\mathrm{Ao}} * 100 \longrightarrow$ (1) 
Where $A_{o}$ is the absorbance of the control response, and $A_{1}$ is the absorbance within the sight of the examples or benchmarks.

\subsubsection{Statistical analysis}

The outcomes were communicated as mean \pm standard/deviation and the factual importance of contrasts were resolved worker one/route examination of change (ANOVA/SPSS/17.0). Contrasts were viewed as critical at $\mathrm{P}<0.05$. The qualities are exhibited as mean \pm SD $(n=3)$.

\section{Results and Discussion}

\subsection{Chemistry}

The reactions for the synthesis of the new compounds, namely, [2-amino-4-(3,4dichlorophenyl)-5-oxo-4, 5-dihydropyrano (3, 2-c) chromene-3carbonitrile(1), 2-amino-4(3,4-dichlorophenyl)-5-oxo-4, $5-$ dihydropyrano (3, 2-c) chromene-3-carboxylic acid (2), 3-amino-2-((3,4-dichlorophenyl)(2oxo-2H-chromen-3-yl)methyl)acrylic $\quad 2$ chloroacetic anhydride (3), 7-(3,4dichlorophenyl)-10-(chloromethyl) $-6 \mathrm{H}$ chromeno [3', 4': 5,6] pyrano [2,3-d][1,3] oxazine-6,8(7H)-dione (4)], were successfully synthesized and completed under conventional. All compounds were synthesized by the reaction of 4hydroxycoumarin, malononitrile, and aromatic aldehydes (3,4-dichlorobenzaldehyde) with various catalysts (tetrabutylammonium bromide (TBAB) as a catalyst for synthesis of compounds: method (a) using diammonium hydrogen phosphate (DAHP) as catalyst for synthesis of compounds method (b).

\subsection{Antioxidant assay}

Antioxidant activities of ombined mixes were performed utilizing different in vitro tests against 1, 1-diphenyl-2-picrylhydrazyl (DPPH) radical.

\subsubsection{DPPH Scavenging Activity of Compounds (1-4)}

The function of an antioxidant is expel free radicals. One vital system of such removal is by donating hydrogen to free radicals in its reduction to nonreactive species [23]. The addition of hydrogen would remove the odd electron feature, which is responsible for radical reactivity. Free radicals have been a subject of significant interest among scientists in the past decade. The antioxidant activities of compounds (1-4) were screened in vitro using DPPH (2, 2-diphenyl-1-picrylhydrazyl) radical scavenging methods. Gallic acid was used as the standard. Hydrogen-giving action, as estimated utilizing DPPH radicals as hydrogen acceptor, demonstrated that huge affiliation could be found between the grouping of the new orchestrated particle and the level of restraint[24-28].DPPH compounds (1-4) have been shown to reduce the stable radical. According to Fig.(3) the synthesized compounds $1,2,3$, and 4 possess $63 \pm 0.6 \%$, $88 \pm 1 \%, 83 \pm 0.5 \%$, and $70 \pm 0.8 \%$ DPPH radical-scavenging activity. The compounds $(1,2$, and 3$)$ contain the N-H group, which enables hydrogen atom transfer (HAT) to the DPPH free radical to provide a resonancestabilized radical. The scavenging effect increased with increasing concentrations of the test compounds. In the DPPH method, the maximum scavenging activity was $92.3 \pm 1 \%$ at a concentration $1000 \mu \mathrm{g} / \mathrm{mL}$ for compound (2), and the minimum scavenging activity was $25.5 \pm 0.5 \%$ at a concentration of $250 \mu \mathrm{g} / \mathrm{mL}$ for compound (1). Fig.(4) show the proposed mechanism for the compounds, namely, 2amino-4-(3, 4-dichlorophenyl)-5-oxo-4, 5dihydropyrano $(3,2-c)$ chromene-3-carboxylic acid (2), and 3-amino-2-((3,4dichlorophenyl)(2-oxo-2H-chromen-3yl)methyl)acrylic 2-chloroacetic anhydride (3). 


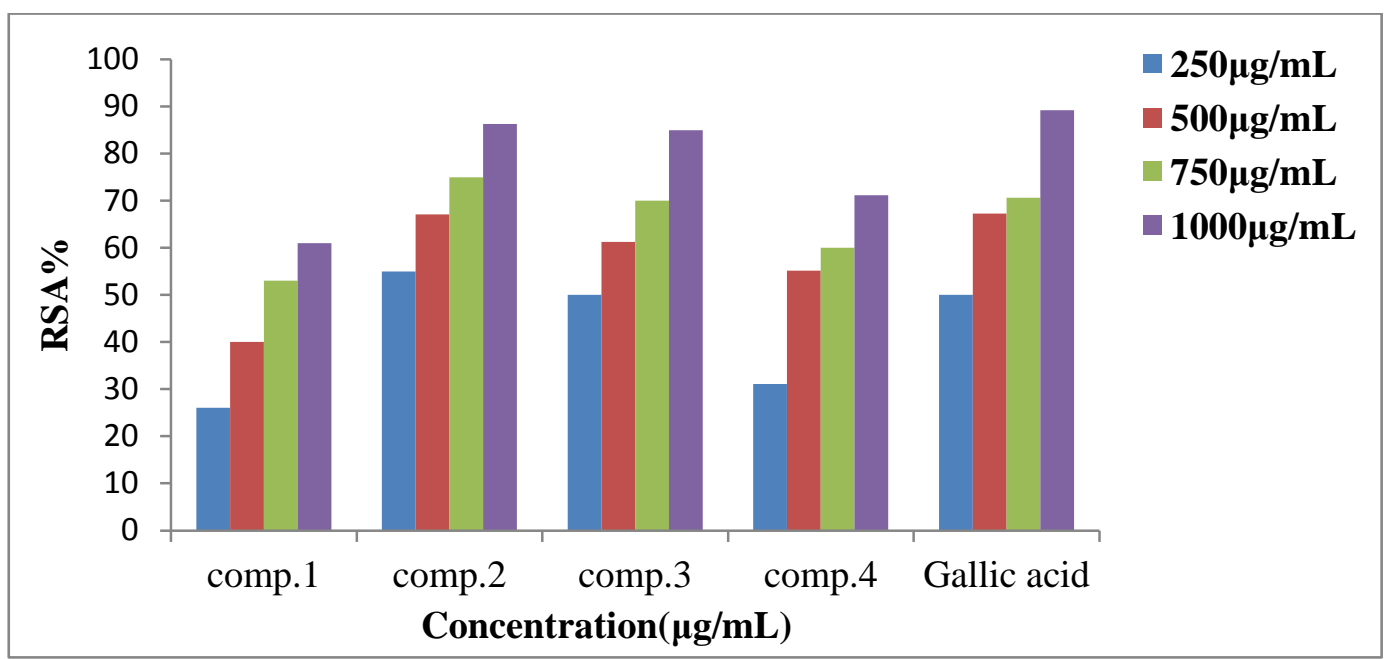

Fig.(3): Effect of compound 1-4 toward DPPH.
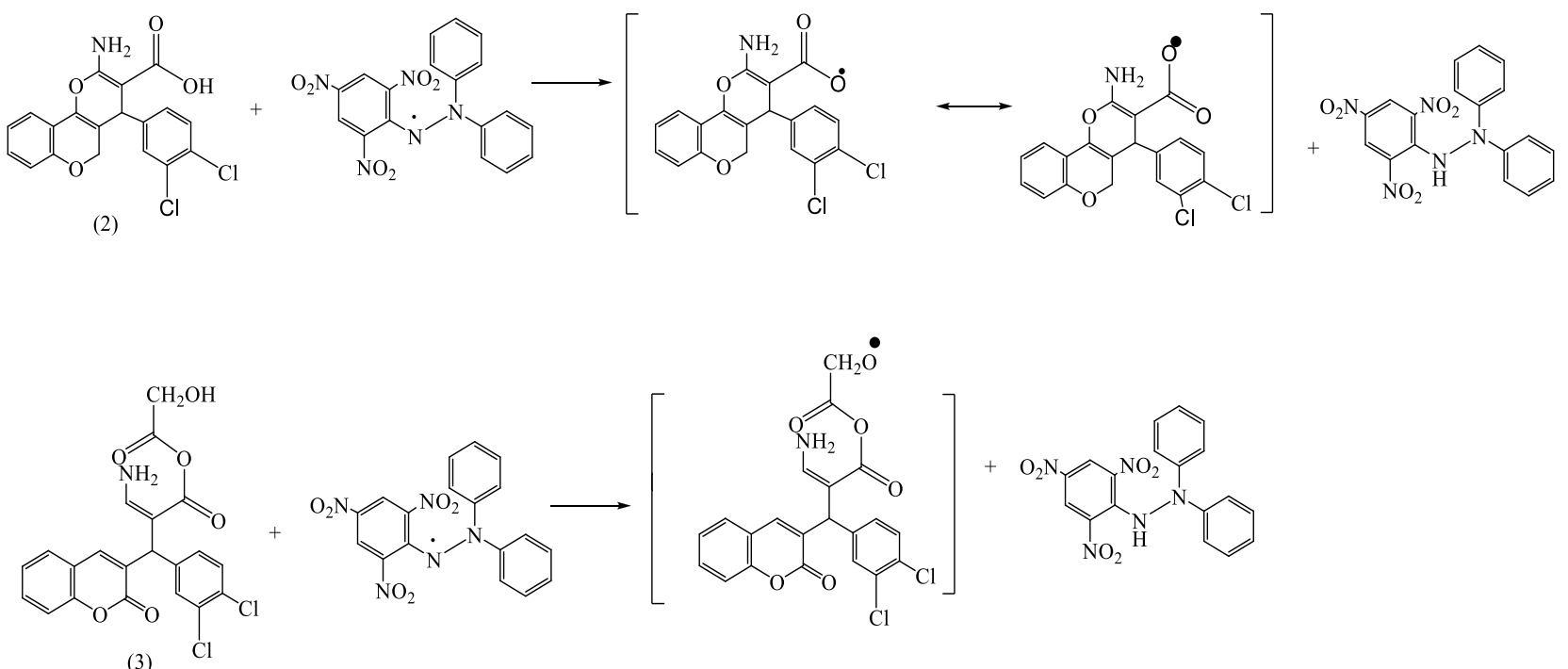

Fig.(4): The reaction between DPPH free radicals and compounds 2 and.

\section{Conclusion}

The preparation and characterization of coumarin derivatives is of considerable interest owing to their potential for various applications based on their biological activity. A series of 4-hydroxy coumarin derivatives were successfully synthesized using conventional methods. The newly synthesized compounds were characterized by using elemental analysis (CHN) and spectroscopic methods (IR and ${ }^{1} \mathrm{H}$ and ${ }^{13} \mathrm{C}$ NMR). The scavenging activities of target compounds have been computed through employee the DPPH radical scavenging assay. Results indicate that the new coumarins possess higher scavenging activity compared with gallic acid as standards.

\section{Acknowledgment}

This study was supported by the Branch of Chemistry, Department of Applied Science, University of Technology (UOT), Baghdad , Iraq.

\section{Referance}

[1] Mahantesha Basanagouda Manohar V., "Synthesis of some new 4aryloxmethylcoumarins and examination of their antibacterial and antifungal activities". Journal of chemical sciences, 121(4): 485495, 2009.

[2] Omaima Mohamed Abd Elhafez, Ezz El Din Ahmed Mohamed El Khrisy,Farid Badria,Alaa El Din Mohamed Fathy, "Synthesis and biological investigations of 
new thiazolidinone and oxadiazoline coumarin derivatives". Archives of pharmacal research, 26(9): 686-696, 2003.

[3] Trapkov, V., E. Parfenov, and L. Smirnov, "Synthesis and antiulcer activity of copperand zinc-containing coumarin antioxidants". Pharmaceutical chemistry journal, 30(7): 445-447, 1996.

[4] El-Fattah, M.A., MY El-kady, "Synthesis and Biological Evaluation of Some Coumarin Derivatives". in 14th Int. Electron. Conf. Synth. Org. Chem. 2010. MDPI.

[5] Ahmed A. Al-Amiery, Yasameen K. AlMajedy, Abdul Amir H. Kadhum \& Abu Bakar Mohamad, "Novel macromolecules derived from coumarin: synthesis and antioxidant activity". Scientific reports, 5. 2015.

[6] Anne A. Emmanuel- Giota Konstantina C. Fylaktakidou Konstantinos E. Litinas Demetrios N. Nicolaides Dimitra J. Hadjipavlou- Litina, "Synthesis and biological evaluation of several 3(coumarin- 4- yl) tetrahydroisoxazole and 3- (coumarin- 4- yl) dihydropyrazole derivatives". Journal of Heterocyclic Chemistry, 38(3): 717-722, 2001.

[7] Hamdi, N. and P. Dixneuf, "Synthesis of Triazole and Coumarin Compounds". Topics in Heterocyclic Chemistry, 2007.

[8] M. M. MarchenkoG. P. Kopyl'chukI. A. ShmarakovO. V. KetsaV. N. Kushnir, "Synthesis and antitumor activity of 5-(5', 6'-benzocoumaro-3'-yl) methylaminouracil hydrobromide and its liposomal medicinal form". Pharmaceutical Chemistry Journal, 40(6): 296-297, 2006.

[9] Halliwell, B., Food-derived antioxidants. "Evaluating their importance in food and in vivo". Food science and agricultural chemistry, 1999.

[10] M.Moro, Mariele Charão, Natália Brucker, Rachel Bulcão, Fernando Freitas," Effects of low-level exposure to xenobiotics present in paints on oxidative stress in workers". Science of the total environment, 408(20): 4461-4467, 2010.

[11] Ramin Miri,Hamideh Saadati,Pegah Ardia,Omidrez Firuzia, "Alterations in oxidative stress biomarkers associated with mild hyperlipidemia and smoking". Food and chemical toxicology, 50(3): 920-926, 2012.

[12] Ames, B.N., M.K. Shigenaga, and T.M. Hagen, "Oxidants, antioxidants, and the degenerative diseases of aging". Proceedings of the National Academy of Sciences, 90(17): 7915-7922, 1993.

[13] Shahidi, F., "Natural antioxidants: chemistry, health effects, and applications". The American Oil Chemists Society, 1997.

[13] Marja P. Kähkönen, Anu I. Hopia, Heikki J. Vuorela, Jussi-Pekka Rauha, Kalevi Pihlaja, Tytti S. Kujala, and Marina Heinonen., "Antioxidant activity of plant extracts containing phenolic compound". Journal of agricultural and food chemistry, 47(10): 3954-3962, 1999.

[14] Al-Azzawie, H.F. and M.-S.S. Alhamdani, "Hypoglycemic and antioxidant effect of oleuropein in alloxan-diabetic rabbits". Life sciences, 78(12): 1371-1377, 2006.

[15] Khurana, J.M. and S. Kumar, "Tetrabutylammonium bromide (TBAB): a neutral and efficient catalyst for the synthesis of biscoumarin and 3, 4dihydropyrano [c] chromene derivatives in water and solvent-free conditions". Tetrahedron Letters, 50(28): 4125-4127, 2009.

[16] Abdolmohammadi, S. and S. Balalaie," Novel and efficient catalysts for the one-pot synthesis of 3, 4-dihydropyrano [c] chromene derivatives in aqueous media". Tetrahedron Letters, 48(18): 3299-3303, 2007.

[17] Alicia E. Reid, Sung Won Kim ,Brienne Seiner, Frank W. Fowler, Jacob Hooker, Richard Ferrieri, Benjamin Babst, Joanna S. Fowler, "Radiosynthesis of C- 11 labeled auxin (3- indolyl [1- 11C] acetic acid) and its derivatives from gramine". Journal of Labelled Compounds and Radiopharmaceuticals, 54(8): 433-437, 2011.

[18] Patel, H., H. Desai, and H. Mistry, "Synthesis and antimicrobial activity of some new piperazine derivaties containing aryl sulfonyloxy group". Journal of Chemistry, 1(2): 93-98, 2004.

[19] Serban, G., "5-Arylamino-1, 3, 4thiadiazol-2-yl acetic acid esters as 
intermediates for the synthesis of new bisheterocyclic compounds". Farmacia, 63: 146-149, 2015.

[20] Abdul Amir H. Kadhum1, Ahmed A. AlAmiery, Mukaram Shikara, AbuBakar Mohamad1, "Synthesis, structure elucidation and DFT studies of new thiadiazoles". International Journal of Physical Sciences, 6(29): 6692-6697, 2011.

[21] Abdul Amir H. Kadhum, Ahmed A. AlAmiery, Ahmed Y. Musa, Abu Bakar Mohamad, "The antioxidant activity of new coumarin derivatives". International journal of molecular sciences, 12(9): 5747-5761, 2011.

[22] Abdul Amir H. Kadhum, Abu Bakar Mohamad, Ahmed A. Al-Amiery, Mohd S. Takriff, "Antimicrobial and antioxidant activities of new metal complexes derived from 3-aminocoumarin". Molecules, 16(8): 6969-6984, 2011.

[23] Khalid Hamid Musa,Aminah Abdullah, Khairiah Jusoh, Vimala Subramaniam, "Antioxidant activity of pink-flesh guava (Psidium guajava L.): effect of extraction techniques and solvents". Food Analytical Methods, 4(1): 100-107, 2011.

[24] Halliwell, B., 'Reactive oxygen species in living systems: source, biochemistry, and role in human disease". The American journal of medicine, 91(3): S14-S22, 1991.

[25] Mario Foti, Mario Piattelli, Maria Tiziana Baratta, Giuseppe Ruberto, "Flavonoids, coumarins, and cinnamic acids as antioxidants in a micellar system. Structureactivity relationship". Journal of Agricultural and Food Chemistry, 44(2): 497-501, 1996.

[26] Duh, P.-D., Y.-Y. Tu, and G.-C. Yen, "Antioxidant activity of water extract of Harng Jyur (Chrysanthemum morifolium Ramat)'. LWT-Food Science and Technology, 32(5): 269-277, 1999.

[27] Guoa JijunYanga, Jing yuWeia, YunfengLia, JingXua, YugangJiang," Antioxidant activities of peel, pulp and seed fractions of common fruits as determined by FRAP assay". Nutrition Research, 23(12): 1719-1726, 2003. 